\title{
Retraction Note to: A survey on human-computer interaction technologies and techniques
}

\author{
Haitham Badi' ${ }^{1,2}$ - Mohammed Fadhel ${ }^{1} \cdot \operatorname{Sana}_{\text {Sabry }}{ }^{1} \cdot$ Mohamed Jasem $^{3}$
}

Published online: 13 March 2017

(C) Springer International Publishing Switzerland 2017

\section{Retraction Note to: Int J Data Sci Anal (2016) 2:1-11 DOI 10.1007/s41060-016-0018-x}

The Editor-in-Chief and the publisher retract the abovementioned article per the Committee on Publication Ethics (COPE) guidelines on self-plagiarism. The article has significant overlap with two other publications by the same coauthor:
- Haitham Hasan, Sameem Abdul-Kareem, HumanComputer Interaction Using Vision-Based Hand Gesture Recognition Systems: A Survey, Neural Computing and Applications (2013) 25:2. doi:10.1007/s00521-0131481-0

- Haitham Badi, A Survey on Recent Vision-Based Gesture Recognition, Intelligent Industrial Systems (2016) 2:2. doi:10.1007/s40903-016-0046-9

The online version of the original retracted article can be found under doi:10.1007/s41060-016-0018-x.

Haitham Badi

haitham.um.edu.my@gmail.com

1 College of Business Informatics, University of Information

Technology and Communications, Baghdad, Iraq

2 Faculty of Computer Science and Information of Technology, University of Malaya, 50603 Kuala Lumpur, Malaysia

3 Al Yarmouk University College, Diala, Iraq 